\title{
Use of airborne precautions for COVID-19 outside "AGPs" in healthcare settings
}

Tom Lawton ${ }^{1}$, Matt Butler ${ }^{1}$, Christine Peters ${ }^{1}$, Eilir Hughes ${ }^{1}$, Huw Waters ${ }^{1}$, David

Tomlinson $^{1}$, and Lindsay Fraser-Moodie ${ }^{1}$

${ }^{1}$ Affiliation not available

September 24, 2021

\section{Link to published version}

\section{Use of airborne precautions for COVID-19 outside "AGPs" in healthcare settings}

Tom Lawton, Consultant Critical Care, Bradford Teaching Hospitals NHS Foundation Trust

Matt Butler, Consultant Geriatrician, Cambridge University Hospitals NHS Foundation Trust

Christine Peters, Consultant Microbiologist, NHS Greater Glasgow and Clyde

Eilir Hughes, General Practitioner, Ty Doctor, Nefyn, Gwynedd

Huw Waters, Consultant Risk Analytics, FreshAir.Wales

David Tomlinson, Consultant Cardiologist, University Hospitals Plymouth NHS Trust

Lindsay Fraser-Moodie, GP Trainee, East of England Deanery

On behalf of FreshAir NHS

28th June 2021

Since the early days of the pandemic there has been debate as to whether COVID-19 transmission can be airborne, and whether healthcare workers require routine airborne precautions, or if respiratory PPE can be preserved for a small list of "Aerosol Generating Procedures". ${ }^{[1]}$ The former question is now largely satisfied COVID-19 is airborne ${ }^{[2]}$ - but the latter remains and official UK guidance leaves the matter up to individual NHS Trusts to decide. ${ }^{[3]}$

FreshAir NHS is a group of frontline NHS workers who wrote an open letter signed by over 1,600 colleagues to all governments of the UK nations in January 2021 requesting airborne mitigations to prevent infections in healthcare staff and reduce nosocomial infection risk to patients. ${ }^{[4]}$ 
We therefore welcome pragmatic data from Ferris, Ferris et al showing that a simple substitution of filtering face piece (FFP3) respirators for fluid resistant surgical masks (FRSM) appeared to eliminate $100 \%$ of the 47-fold increase in excess risk of COVID-19 infection in healthcare workers (HCWs) caring for patients on COVID-19 "red" wards. ${ }^{[5]}$ Prior to the introduction of FFP3, HCW infection rates on "red" wards were greater than those on "green" wards, and also demonstrated no correlation with community case rates, suggesting infections resulted from direct patient care - in line with genomic evidence that a large proportion of HCW infections are transmitted from patients. ${ }^{[6]}$ Some studies have suggested that staff infection rates merely reflect transmission in the community such that staff rates increase as community rates rise and are therefore inevitable. ${ }^{[7,8]}$ This study highlights that this is only true for non-COVID-19 facing staff, with exposure to infected patients being the driving factor for infections in COVID-19 facing staff.

This has important implications for healthcare worker protection as the UK copes with what is hopefully an "exit wave" as well as trying to reduce the massive backlog of other work whilst coping with inevitable staff sickness and isolation. It also touches on our responsibility as a learning healthcare system to ensure preparedness for future epidemics and pandemics.

However, if the precautionary principle were the only factor to consider then the UK would have used airborne precautions from the start of the pandemic - so clearly there are other factors to address. PPE was in short supply in early $2020,{ }^{[9]}$ which may have made rationing more appropriate, but supply chains have largely recovered - and reusable PPE has both environmental and cost savings. ${ }^{[10]}$ Fit-testing staff adds burden to infection control teams, but NHS trusts which have made the switch have demonstrated it is possible, and there is evidence that reusable elastomeric respirators (but not disposable FFP3 masks) may be used safely with a "fit check" alone. ${ }^{[1]}$ It is clear that tighter-fitting masks can be less comfortable particularly if the fit is not suitable for the user, but surveyed staff appear in general to prefer the higher level of protection. ${ }^{[12]}$ Most healthcare staff are now vaccinated, but the B1.617.2 (delta) variant appears to reduce vaccine effectiveness at a time when staff absences due to sickness and isolation can critically hamper NHS recovery as patients await delayed treatment. ${ }^{[13]}$

The only remaining argument appears to be that we are beholden to the past; that to change guidance now would be to admit that mistakes were made. Whilst this may have a powerful emotional hold on local and national policymakers and leaders; the best pandemic responses have come when we have learned and changed course when necessary: "Progress is impossible without change; and those who cannot change their minds cannot change anything." "[14]

\section{Competing interests}

TL, MB, CP, EH, DT, LF-M are practising NHS clinicians and subject to UK PPE guidance

\section{References}

[1] Hamilton F, Arnold D, Bzdek BR, Dodd J, White C, Murray J, et al. Aerosol generating procedures: are they of relevance for transmission of SARS-CoV-2? Lancet Respir Med 2021. https://doi.org/10.1016/ S2213-2600 (21) 00216-2.

[2] Tang JW, Marr LC, Li Y, Dancer SJ. Covid-19 has redefined airborne transmission. BMJ 2021;373:n913. https://doi.org/10.1136/bmj.n913.

[3] COVID-19 infection prevention and control guidance - Version 1.2. London: PHE; 2021. Report No.: GOV-8505.

[4] Wise J. Covid-19: Doctors and nurses demand better PPE for wider range of procedures. BMJ 2021;372:n30. https://doi.org/10.1136/bmj .n30. 
[5] Ferris M, Ferris R, Workman C, O'Connor E, Enoch DA, Goldesgeyme E, et al. FFP3 respirators protect healthcare workers against infection with SARS-CoV-2. Authorea Prepr 2021. https://doi.org/ 10.22541/au.162454911.17263721/v1.

[6] Illingworth C, Hamilton W, Warne B, Routledge M, Popay A, Jackson C, et al. Superspreaders drive the largest outbreaks of hospital onset COVID-19 infection. OSF Prepr 2021. https://doi.org/10.31219/ osf.io/wmkn3.

[7] Treibel TA, Manisty C, Burton M, McKnight Á, Lambourne J, Augusto JB, et al. COVID-19: PCR screening of asymptomatic health-care workers at London hospital. The Lancet 2020;395:1608-10. https: //doi.org/10.1016/S0140-6736(20)31100-4.

[8] Brown CS, Clare K, Chand M, Andrews J, Auckland C, Beshir S, et al. Snapshot PCR surveillance for SARS-CoV-2 in hospital staff in England. J Infect 2020;81:427-34. https://doi.org/10.1016/j.jinf . 2020.06 .069 .

[9] Hoernke K, Djellouli N, Andrews L, Lewis-Jackson S, Manby L, Martin S, et al. Frontline healthcare workers' experiences with personal protective equipment during the COVID-19 pandemic in the UK: a rapid qualitative appraisal. BMJ Open 2021;11:e046199. https://doi.org/10.1136/bmjopen-2020-046199.

[10] Higgins GC, Ho J, Robertson E, McLean N, Horsley C, Douglas J. Covid-19: Health and social care workers need, want, and deserve reusable FFP3 respirators. BMJ 2021;372:n759. https://doi.org/10. $1136 / \mathrm{bmj} . \mathrm{n} 759$.

[11] McMahon K, Jeanmonod D, Check R, Rivard L, Balakrishnan V, Kelly B, et al. The pragmatic use of industrial elastomeric facemasks in health care practice during the COVID-19 pandemic. Am J Emerg Med 2021;48:273-5. https://doi.org/10.1016/j.ajem.2021.05.025.

[12] Butler M, Inkster T, Foster C, Lawton T, Hughes E, Waters H, et al. Effect of Implementation of Aerosol Respiratory Protective Equipment, Vaccination and Natural Infection on a Covid-19 Cohort Ward: A Retrospective Observational Cohort Study. OSF Prepr 2021. https://doi.org/10.31219/osf .io/nh5sr.

[13] SARS-CoV-2 variants of concern and variants under investigation. London: PHE; 2021. Report No.: GOV-8715.

[14] Shaw GB. Everybody's political what's what. Constable and Company Limited, London; 1945. 